\title{
Turnover in the Advancement Profession
}

Received (in revised form): February 13, 2006

\section{Jon D. Iarrobino}

Dr. Jon D. Iarrobino is Assistant Vice President for Advancement Services, and Director of Organizational Development and Human Capital Management at Carnegie Mellon University in Pittsburgh, Pennsylvania. In this leadership role, Dr. Iarrobino is responsible for organizational development and effectiveness strategies in University Advancement while serving as deputy of the Advancement Services Group. His work in organizational development/effectiveness has been groundbreaking for the division and has helped it reach a new level of cross-university and intradepartmental collaboration, resulting in more effective programs and improved productivity. He sits on the division's senior management team. Prior to his current appointment, he served the division as Director Development Strategic Planning and Analysis.

Dr. Iarrobino earned his Doctor of Education degree from Boston University's School of Education in Administration, Training \& Policy Studies. His research interest is in the area of human capital investment in institutions of higher education and other nonprofits. While earning his doctorate full-time, he worked in higher education advancement full-time, first as Director of the Parents Program at Emerson College and then as the Major Gifts Officer at Boston University's School of Management. He has established his own non-profit foundation and serves on the Alumini Board of Directors at Emerson College and Boston University School of Education.

\begin{abstract}
Recruitment and retention is an area with which most organizations are concerned. Excessive turnover has exorbitant costs and wastes valuable time. Institutions of higher education are no exception. One of the most vital operations in nonprofit colleges and universities is its Office of Institutional Advancement. More and more, an institution of higher education's ability to achieve its vision and goals is dependent on the state of
\end{abstract}

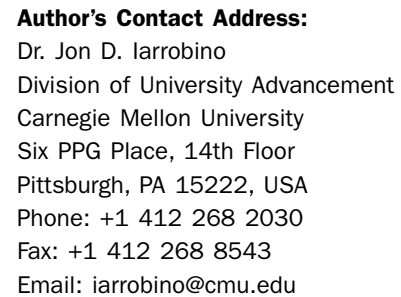

its endowment, yearly grants (research or otherwise), annual fund donations, and other development income. These development initiatives require a dedicated staff, willing to spend months, even years cultivating donors of all levels.

There is an epidemic of turnover in the advancement profession. It is a problem to which higher education professionals need to pay attention. With consistent and constant turnover of advancement professionals, colleges and universities are losing precious resources, not only in costs associated with personnel turnover, but also the loss of valuable donor-professional relationships and ultimately, in the loss of gifts.

This article analyzes this turnover problem at the national and local 
levels. A description and documentation of the problem will be outlined, followed by careful analysis. The description and documentation of the problem will highlight its severity. The study is grounded locally in data from a small New England college. Lastly, a series of policy recommendations will be presented.

International Journal of Educational Advancement (2006) 6, 141-169. doi:10.1057/palgrave.ijea.2150013

\section{Keywords:}

fund raising, retention, staff development, turnover

\section{The Problem}

\section{General description and background of the problem}

Research, capital projects, dormitories, science labs, libraries, professors' salaries, student activities, athletics, scholarships, administration, and support staff are just a few of the "products" advancement professionals must sell to their donors. Philanthropy has been an American tradition for centuries, most notably by successful business professionals such as Carnegie, Rockefeller, and most recently Gates. However the mere survival, and the ways in which colleges and universities thrive, is ever-increasingly dependent on their financial resources. Tuitions continue to rise and generally cover only $60-80 \%$ of operating budgets. Therefore, universities and colleges are becoming more and more dependent on their advancement operations.

With the highlighted importance of supplemental funds, the demand for good fundraisers is at an all time high. Retaining top talent in advancement offices should be a primary goal for higher education senior administrators. Despite the pressures from presidents and chancellors on their vice presidents of advancement to increase their giving numbers, they often fail to realize how important taking care of their staff directly affects their success. Most higher education advancement professionals leave their positions because of lack of growth within the college or university (Thomas, 1996). In a 1995 study on turnover in the higher education advancement profession, Edward G. Thomas, Associate Dean of the James J. Nance College of Business Administration at Cleveland State University, discovered that 48 percent of advancement officers who left their positions that year did so to achieve higher rank, more opportunity for advancement, or better salary and benefits (Thomas, 1996).

Thomas (1996) found that more than half of the employees who left their advancement jobs in 1995 had been working in their department for more than one year, but less than five. Considering the time it takes to cultivate and steward a major donor (six-figure gifts and higher), it is evident that colleges and universities are not only incurring the high costs of turnover in general, development turnover is more devastating to the bottom line. "After all, without special handling, turnover and transition among [advancement] staff can set back fund-raising progress for months or even years" (Helm, 1993).

The average length of time it takes to close a charitable gift varies. With luck, a donor ready to make a gift, can call an advancement professional and contribute money instantly. However, according to Paulette 
Maehara, the president and CEO of the Association of Fundraising Professionals (AFP), a more likely scenario could take anywhere from six months to ten years, depending on the size and type of gift. Most gifts do not come without a lot of donor research, donor relationship building, internal strategy development, and alignment of key interests between an institution and a donor. Smaller gifts tend to take less time; in general, larger gifts have longer cultivation periods. However, smaller gifts can turn into larger gifts with the right cultivation. For instance, naming a school at a university for multimillions of dollars can take several years, but can include several smaller gifts to the school and can be included in the overall price tag of naming the institution.

Development officers-good ones, anyway-work hard to build and nurture a wide-ranging network of friendships that bind people to their alma mater. They are in the words of Trinity College's former Vice President for College Advancement Karen

Osborne and now consultant, "honest brokers" to whom perspective donors entrust their dreams as well as highly personal financial and family information (Helm, 1993).

Oftentimes, advancement professionals establish close relationships with their donors. After all, development officers spend hours and hours over many meals discussing intimate details of their prospects' lives. Moreover, more often than not, prospective donors become actively involved with the life of the institution they hope to support. They attend events, speak to classes, give lectures to larger classes, or serve on boards or other governing bodies.

The impact of a departing development officer can be devastating to fund-raising goals. Changes in staff can confuse donors, complicate giving inclinations, and hurt the morale of the donors. Losing continuity means losing momentum, and in development, losing momentum translates into losing money. If a staff member has been working with a donor for two years and he or she leaves, perhaps only months away from closing a gift, the donor is affected. Not only is the donor affected, but various constituencies within the organization are either directly or indirectly affected, as well. When a donor's primary relationship to the university or the college is compromised, his or her gift will, too be compromised. Without individual donors, programs go unsupported, and an array of financial needs is not met.

\section{Importance of the problem}

Though many academicians resist the notion that education is, in part, a business, this problem illustrates the importance of the management of people and its relationship to managing assets. Without money, organizations cannot function. Tuition is only one source of income, and generally speaking, only partially covers the operation budgets of most higher education institutions. Therefore, prudent fiscal management is essential to survival and growth. Without successful advancement operations, a university or college is thwarted.

Inconsistent advancement staffs and poor fund-raising achievement affect 
everyone in higher education institutions. School rankings are directly affected by the quality of the faculty and faculty salaries are oftentimes directly related to fundraising achievement. An endowed professorship, usually a \$2-3 million gift, ensures a competitive salary and benefits, research funds, and other benefits for universities or colleges to attract first-rate scholars. First-rate scholars will be enticed by those institutions that will pay for their skills, knowledge, and expertise.

Another school ranking indicator is the quality of the students-most easily measured by the mean standardized test score. More often than not, the students with the highest standardized test scores also have the highest grade point averages and carry many extracurricular activities at the same time. Those students win meritbased scholarships, which are funded by alumni, friends, or parents of the institution. Without precious scholarship money, high-quality and competitive students may be lost to institutions that offer them greater financial support.

The assets to which the institution has access directly affect the overall quality of the institution and the education the institution provides. More broadly, they affect the quality of education that our nation is committed to providing. On some levels, that is up to the people, the organizations, and the government officials who choose to support education. But it is truly up to the advancement team to promote professionalism, stability, and confidence to potential donors. With constant fluctuation, confidence is lowered and bottom lines suffer.
“Anytime there's a change in people, you have to secure a renewed understanding of what the relationships and expectations are" (Shoemaker, 1995, p. 19). Time is money. And in higher education, money is one of the key determining factors in the quality of education it provides.

Development professionals, too, are affected by the turnover dilemma. The profession is known for its high burnout and high turnover. "Ask around about the down sides of working in advancement, and you may expect to hear the word, 'burnout.' Not surprisingly, you might also hear the term, 'high turnover" (Thomas, 1996, p. 29).

\section{The problem on a national scale}

"One of the roughest parts [of] turnover in [advancement] staff is replacing those experienced not only in the techniques of fund raising but in the deep knowledge of their institution [and their donors]" (Shoemaker, 1995, p. 19). Many administrators and researchers have documented that turnover in the development field is high, but few have focused on why. Margaret Duronio, director of planning and administration at the University of Pittsburgh says that "too many nonprofits fail to provide optimum working conditions for effective development programs or competent fund raisers" (Duronio, 1996, p. 64).

In Edward G. Thomas' (1996) study on turnover, he surveyed 3,322 advancement professionals and found 460 job changes, both voluntary and involuntary. The turnover rate for surveyed advancement professionals in 
1995 was $13.8 \%$. It was evident that advancement had higher turnover rates than most other departments within higher education. Given the relationship between advancement personnel and donors explicated earlier in this paper, one can reasonably assert that the financial losses incurred due to these high turnover rates are well into millions of dollars nationally. To better understand the significance of the problem, it is helpful to ground the issues with data from a specific institution.

\section{The problem at College A (investigation completed in 2003)}

College A has had high levels of turnover in its Office of Institutional Advancement (OIA), most notably in the past ten years. The office houses development, alumni relations, corporate and foundation relations, and public affairs. There is a vice president for the OIA, an associate vice president for Public Affairs, four directors, two associate directors, and ten staff members. The office has a total of 18 employees. Over the past ten years there have been several vice presidents and only a small number of staff has been in his or her position for longer than three years.

College A's endowment is fairly small compared to its competitor institutions. The college is highly tuition driven. The five-year strategic plan is ambitious in a variety of areas, including capital projects, increasing its endowment, raising its national brand recognition, and improving the quality of most of its programs. In order to achieve its goals, resources are needed. College A's alumni support it only minimally through annual giving. The OIA's turnover problem exacerbates the alumni giving problem at both the annual giving and major giving levels.

Development and alumni relations rely heavily on relationship building, stewardship, and continuity of direct mail marketing initiatives. New vice presidents and a revolving staff means that internal missions are constantly changing and so are the managers of the donor prospects. Alumni, parents, and friends of the college see the constant turnover and perceive a serious problem within the office. The turnover contributes a great deal to loss of gift income. In the past, donors have not received acknowledgements of their gifts, their names have been spelled incorrectly on programs or naming gifts, and addresses are lost and not up to date. Without a highperforming office, donations do not increase.

In the past three years, there have been few months when the office was not looking to fill a vacant position. The long-term effects are already visible. Alumni giving rates continue to be low, the office has gained a reputation as an uncomfortable place to work, and people keep leaving. In one month the office had five resignations. Six months later, four other staff members quit. And three months later, College A lost another one of its vice presidents, whose tenure was only about three years.

Problem stakeholders at College A Positive stakeholder-or people who have a vested interest in the problem (Gaynor, 1998)—at College A include members of the OIA directors' council. 
Many of these members feel very strongly about reducing the office's turnover rate. It affects them directly as their success depends on their staff's productivity and effectiveness. A turnover epidemic will only undermine their hard work.

The latent stakeholders-those who could make a difference if they were informed and recruited (Gaynor, 1998) - are alumni and future alumni of the college and the board of trustees. Other department heads are also latent stakeholders as the reputation of the office is well known throughout the college and its turnover affects their jobs indirectly, as well.

It will become more evident through the analysis who the negative stakeholders are at College A. Negative stakeholders can be described as those who exacerbate, or actually prevent the problem from getting resolved (Gaynor, 1998).

\section{Problem stakeholders on the national level}

It is important to think about the turnover problem stakeholders at the national level. Because turnover in the advancement field in higher education has caught the attention of many across the nation, understanding who can change the problem is important.

An international organization for advancement professionals in education, CASE should have a major interest in improving the turnover problem that is plaguing the field. Over the years, CASE has worked hard at changing the perceptions of advancement professionals. CASE should see it in their best interest and in their members' best interests to help find ways for advancement professionals to stay in their jobs longer. Therefore, CASE and other national organizations for higher education advancement professionals are positive stakeholders at the national level.

University executives, those who manage the vice presidents for advancement operations, must realize that high turnover in their advancement group means losing money for the university. Nonetheless, those with seemingly the most power do very little to change the problem. As the analysis will point out, turnover in the advancement operation has a lot to do with personnel policies. Usually those who set those policies are the chief executive officers of the institution.

Especially in the advancement field, where there is pressure to perform by bringing in dollars, university executives complicate matters by ignoring their most prized asset, their people. Frequently, vice presidents of advancement or development have limited authority in their personnel procedures.

Because advancement budgets are approved or disapproved by presidents or executive vice presidents for finance and administration, advancement vice presidents' authority is undermined. Ten advancement professionals from colleges or universities from New England were called and asked two specific questions. The first question was: do you think vice presidents for development or advancement have complete control over their personnel budget and decision-making? Nine out of ten of them said no. The second question was: if not, then who does? Answers varied from chancellors, presidents, executive vice presidents, 
and vice presidents for administration. For this reason, which will be expounded upon in the analysis and recommendation sections, nonadvancement, university executives are categorized as negative stakeholders.

Latent stakeholders are university advancement professionals. Though they are part of the problem, they could begin to speak about their experiences and reasons for leaving. Several of the professionals from College A refused to be honest when they left the institution in the fear of ruining their own reputation. Just one honest exit interview could make an enormous difference in altering this problem. If advancement professionals themselves were activated, they could help to make a change.

Donors to colleges and universities are also latent stakeholders. The problem is affecting them and their relationships to their alma maters or to institutions to which they chose to support for various reasons. When they lose their frontline representative to competing institutions, there are mutual losses. Donors could begin to speak up to university executives and trustees and ask why so many people are leaving. Because universities aim to please their donors, donors could become a very powerful force in bringing about needed changes.

Lastly, boards of trustees at colleges and universities also hold an enormous amount of authority. If boards were brought into this problem on the micro-level and understood the damage turnover was doing to the financial stability of the institutions, it is likely that trustees would want to do something about the problem.

\section{Proposed Causes of the Problem}

\section{A conceptual framework toward possible causes of the problem} According to the US Department of Labor, it costs an organization (on average) one-third of a new hire's annual salary to replace an employee (Michaud, 2002). This amount can include expenses associated with advertising the position or headhunter fees, management's time involved in interviewing, selection, and training, and decreased productivity. Carol Hacker (2003) agrees and says that "turnover is a silent profit killer" ( $p$. 14). In addition, Hacker argues that turnover creates stress for remaining employees, as they have to get the work done. She says it hurts morale, resulting in emotional and financial losses. Many managers believe that there is nothing that they can do to change turnover trends. Others disagree and believe that turnover has a direct link to people programs. When employers support their people in various ways including, but not exclusively in cash compensation, they stay. "Literature and best practices indicate that if employers treat their employees as valued contributors, the employees will [be loyal]" (Gering and Conner, 2002, p. 14). Managers and executives may have more control over the problem than they think. A review of the turnover and retention literature provides a theoretical framework that outlines the possible causes of high turnover in the advancement profession. The framework can be divided into three parts: recruiting 
strategy, compensation and benefits programs, and other human resources programs.

\section{Recruiting strategy management}

Some (Kay and Phan, 2002; Davenport, 1999) agree that turnover problems begin with poor recruiting. Most employers do not have a recruiting strategy in place. Certainly, when a position becomes vacant, the manager may think about what skills a person needs to perform the job function, but this is not considered as a recruiting strategy. Davenport (1999) argues that an organization must understand how to pinpoint the human capital it needs. Does the company develop employees from within? Does it seek new talent from outside the firm? What are the pros and cons to each? Davenport also suggests that managers need to think about four important elements of recruiting talent: skills, talent, behavior, and knowledge. He argues that many organizations only look for skills, the know-how to do a certain job or function. Skills can be, for example, knowledge of certain software programs, expertise in communication, or negotiations.

One of the most important of the four elements is behavior. How is a person going to fit in the culture of the organization? How is he or she going to interact and relate to his or her colleagues? And in the specific case of advancement personnel, how is the person likely to relate to potential donors? All of these questions should be answered as part of an organization's recruiting strategy. What kind of people is an organization looking for? What kind of talents and skills is the organization looking to attract and retain? What kinds of behaviors? How deep should one's knowledge be in a certain field?

Two leading human capital management thinkers, Ira Kay and Bruce Phau (2002) have done substantial research in the area of recruiting and retention. They say that talent is in short supply and recruiting has an important role in reducing turnover and reducing high costs to organizations. Watson Wyatt Worldwide's (2000) Human Capital Index research shows that all else being equal, companies that have strong recruiting and therefore, retention, are worth 7.6 percent more in the market. Kay and Phau say that the recruiting strategy should support the overall business plan of the organization. Like Davenport, they agree that organizations need to know long before they hire someone, what exactly their goals are and how the right people can get them there. Kay and Phau also argue that though some training is always necessary, employers should hire people who can "hit the ground running” (p. 10).

Along with a strong new-hire orientation, individual assessment is another key component to good recruiting. Detailed questionnaires and pre-screening surveys aligned with the overall recruiting strategy allow firms to weed out those who do not fit. Face to face interviewing is vital, but Davenport (1999) and Kay and Phan (2002) would all agree that behavioral interviewing is the best type of interviewing. "Future behavior is best predicted by past behavior" (Kay and Phan, 2002, p. 29). This type of interviewing seeks specific examples from generalizations candidates make 
about their background, successes, or experiences. The interview, based on the recruiting strategy seeks to find consistency and competence through probing for specific examples to specific questions. In summary, Kay and Phau (2002) provide an excellent outline of the necessary components to a successful recruiting strategy (p. 11).

- A carefully articulated and well-understood business strategy

- Current and comprehensive turnover data, recruitment cost data, and retention data

- Competency models that directly support the business strategy

- A thorough inventory of current competency demographics (where in the organization and with whom do necessary competencies reside? What gap does this recruit fill?)

- Accurate and relevant position descriptions, including a description of career/development tracks

- Intimate knowledge of market/ competitor opportunities along with pay and incentive packages

- A sound candidate evaluation process (systematic rigorous evaluation criteria vis-à-vis skills and competencies, culture, fit, background check, behavioral traits).

Without a methodical and careful approach to recruiting, many organizations find themselves losing people more often. When the employer and employee know what they are getting themselves into, nearly one-third of the turnover battle is won. Retention starts the first day a person is hired. It is vital to make sure an organization is hiring the right individual if they want that individual to stay.

\section{Compensation and benefits programs}

Cash compensation. After hiring an employee, keeping them is another issue. Staying competitive in compensation is critical. Robin Netherton (2002) authors an article describing the recent research on salaries of advancement professionals in higher education conducted by CASE and Carnegie Communications. Though salary is not the sole factor to consider when looking at turnover, it is important for having a grasp of the range of salaries for these professionals.

The survey completed by CASE and Carnegie Communications (Netherton, 2002) found that the typical advancement officers earn between $\$ 40,001$ and $\$ 60,000$ annually-more than one-third of the respondents $(10,063)$ reported salaries in that range. Twenty percent of advancement professionals reported earning salaries in the $\$ 60,001-\$ 80,000$ range and the same percentage one step below at \$20,001-\$40,000. Eleven percent earns between $\$ 80,001$ and $\$ 100,000$ and the same percentage makes more than $\$ 100,000$ annually. Of the top earners, half make \$100,001-\$120,000, and one-quarter make \$120,001-\$140,000, and the other quarter make more than $\$ 140,000$ annually. The research found many different factors that have strong relationships to salary. These factors include sex, level of responsibility, advancement discipline, years in advancement, years at current institution, years in current position, institution type, and district. Those making the most money are usually those managing advancement offices and include several different disciplines (public relations, alumni relations, etc.). 
"The evidence clearly shows the highest turnover among people with fewer than 10 years in the field and those in less senior positions" (Duronio, 1996, p. 3). Though pay is not always the primary reason why people leave a position (Netherton, 2002), many people take other positions to advance their careers (Shoemaker, 1995). It makes sense that young professionals in less senior positions will leave organizations for better opportunities, such as more responsibility and more pay (Helm, 1993). Organizations not only need to pay competitively with similar institutions of similar size, but they also need to offer a competitive edge in their overall compensation packages (Gwynne, 2002). Even in today's economic climate, because of high turnover, advancement professionals have a choice in where they work; inevitably, one of the deciding factors is how much he or she is going to be compensated.

In a survey completed by the American Management Association (AMA), strategies were found that not only cut costs for employers, but also keep valuable staff (AMA, 2002). Benchmarking, comparing one's institution to similar others, is a critical way in which institutions remain competitive (AMA, 2002). "Benchmarking is especially important to nonprofits perhaps because they typically pay less than for profits, and as a result, have higher risks of losing valued employees" (AMA, 2002, p. 3).

Another way of retaining talented employees is by instituting pay for performance. Many businesses have adopted this pay policy and have shown an increase in retention (AMA, 2002, p. 3). When establishing such a policy, HR professionals agree that communicating the plan to employees and educating managers about how to reward workers for their efforts is just vital to the success of such pay programs. When pay-for-performance programs are successfully communicated, organizations have found that people not only work harder, but feel rewarded for their performance. In addition, switching to a base pay/bonus mixture also proved to be a successful strategy. Employees who are paid less in base salary but earn bonuses based on measurable performance also stay in positions longer. Most advancement officers do not work on a bonus structure. Bonuses are sometimes offered to those in the top tier of the salary range, those with the most responsibility, across all advancement disciplines, usually because they hold senior management roles (Thomas, 1996).

Other benefits. Unfortunately, not all organizations can afford to pay their staff at or above market value. In this case, it is important for the organization to admit that it pays below market, and to explain why and whether or not it is attempting to increase its pay scales. Because in higher education institutions, money is often tight, these organizations need to be creative and innovative with the benefits they provide. Vicki Worder (2002) says that “it can't be all about money...accommodating for staff members' life situations with flexibility can go a long way with creating loyalty and [retention]" (p. 71). According to Flannery and Sanes (2003), delivering benefits can have a major impact with employee's 
satisfaction and perceptions. They suggest that organizations offer competitive health-care benefits, including dental plans, and prescription benefits. Corporations, nonprofits and government agencies all have the ability to determine how much of an employee's health insurance they will pay. Flannery and Sanes (2003) suggest that organizations must be vigilant to what competitors are offering. In addition, offering other "perk" benefits are also good retention tools. These benefits can include student aid or tuition remission, stock purchase/stock option plans, and $401 \mathrm{k}$ or 403(b) plans. With $401 \mathrm{k}$ and 403(b) plans, the employer must also consider when they will match their employee's contributions (Flannery and Sanes, 2003). Many higher educational institutions have a vesting period of two years until they will match their employee. More competitive institutions match at a greater level and immediately.

Other benefits that keep talented staff and cost very little money are vacation and sick time or paid time off (PTO) as Ira Kay and Bruce Phan call it Kay and Phan, 2002). Paid time off (PTO) is time that is earned and can be used for any purpose, rather than having separate banks for sick and vacation time. When people are well rested and take the time they need away from the job, they will work better (Kay and Phan, 2002). Paid time off has also been known to decrease fake sick calls. Working from home and flex-time is also another added benefit for some organizations. Many people have to work on weekends or late evenings. When people are awarded flex-time or comp-time for those hours worked, it is another way of letting employees know that they are valued.

Compensation and benefits are not the only factor in helping determine retention, but it is an important component. In short, “organizations should promise employees terrific rewards for terrific performance. They must warn them that poor performance will not be tolerated. Then they must follow through" (Kay and Phan, 2002, p. 86).

\section{Other human resources programs}

There are several different programs or strategies that have nothing to do with money that can combat turnover. Dr. Jacqueline Gish (2003) says that the most important strategy for avoiding turnover is taking responsibility for team morale. Even though it is often tempting to blame upper management, Gish (2003) says that managers of groups or divisions have "a lot of control over local morale” (p. 8). Flannery and Sanes (2003) both academicians and consultants for Ernst \& Young, LLP, argue that the human resources infrastructure is key to retaining people. David Satava, an associate professor of business at the University of Houston also suggests several actionable steps that organization can take to avoid turnover. Satava (2003) argues that "very few people leave a job without good reason" (p. 67). All of these experts agree-that people programs should be the focus of retention strategies. For the purposes of analysis, the other human resources programs section will be broken down into several subcategories.

Creation and communication of a shared vision. With team input, each 
division or department should create its own working vision (Gish, 2003). The vision should be aligned with the overall vision of the organization, but should also be specific to the division's goals. The group should agree upon goals and major milestones should be targeted for future planning (Gish, 2003). After all, people make up the group and their ideas should be valued. When people set goals themselves, they feel responsible for the quality of the work (Davenport, 1999).

Offer praise freely. "As often as possible, compliment your employees on their work. Praise them whenever you can and preferably in public" (Michaud, 2002, p. 36). People need to feel appreciated when they accomplish their goals. Gish (2003) suggests bringing in cakes, group lunches, or presenting awards when team members hold up their end of the bargain. Satava (2003) says that employees work with more enthusiasm for a firm that recognizes their outstanding performance.

Evaluation, development, and promotion from within. Creating solid performance development plans are important to employee retention (Kay and Phan, 2002). Employees respond to employers who let them know where they stand. Honest feedback and evaluation more than once each year ensures that employees know where they stand, where they need to improve, how they can do better (Davenport, 1999). It is equally important to give the employees the resources they need to improve if they are not doing their best. Gish (2003) says it is important to give your staff the tools they need to succeed. Sometimes this does not involve resources, but rather mentoring. "As people grow, give them more responsibility; make sure that people are exposed to all aspects of their job" (Gish, 2003, p. 9).

Satava (2003) encourages the development of a complex professional development plan reflecting employee growth desires and how they are going to reach these higher goals. "Keep developing your team to make your unit as powerful as possible" (Michaud, 2002, p. 36). Send people to training and professional development programs. Flannery and Sanes (2003) urge managers to work to have their evaluation and development programs seen as opportunities rather than evils. An evaluation and development program represents an opportunity for an organization to build its brand internally and keep employees happy. "Staff members who develop deeper skills feel increased satisfaction; personal instruction will encourage employees to feel more valued" (Satava, 2003, p. 67). When employees work hard and develop themselves consistently and positions become vacant, employers should give internal employees the chance to apply for these positions. Not only is an employee already knowledgeable about organizational operations and culture, but it also rewards an employee for his or her hard work (Satava, 2003).

Effective communication. With regular communication comes more security, a better understanding of organizational policy, and greater confidence in management-which leads to employee loyalty (Flannery 
and Sanes, 2003). Communicate on a regular basis, Satava says, by using various modes of communication, such as, e-mail, weekly or monthly meetings, newsletters, or intranets or internal websites. Gish (2003) says that it is vital for organizations to get answers to employee questions, fill out paperwork on time, call meetings that were supposed to be called, and deal with day to day transactions in a timely manner. She also urges against secrets and dishonesty. When people are not communicated to with integrity and respect, they lose faith in the organization and loyalty diminishes (Gish, 2003).

Availability and flexibility. Satava (2003) believes it is vital to create a work environment that lets employees achieve balance. Permit employees to take care of personal needs by coming in late or leaving early. Allow employees to work the hours necessary to get the job done. Satava also believes that leading by example is a way in which managers can be there for their staffs. Gish (2003) believes that retention can be achieved when employers listen to the concerns of their staff members and when action is taken on recommendations. Michaud (2002) agrees and says that employees will tell you their needs and job-related issues. She urges that turnover can be avoided if employers listen to what their employees are telling them and to remove rigidity in policies.

\section{Analysis of the problem at College A considering the relevant research}

The dominant theme of the literature is the focus on the people programs within an organization. When organizations adopt a people-focused orientation, they usually have to invest a significant amount of money. Many chief executive officers in both the business and nonprofit sectors understand the importance of their people, yet do not spend the necessary moneys to make their employees happy. What senior administrators seem to be missing is that high turnover and the costs associated with it far outweighs the costs in investing in the programs that can prevent turnover in the first place (Miskel and Ogawa, 1988). Looking closely at a local example and analyzing the problem at a place like College A, can help illuminate the problem's severity.

Many colleges and universities are grappling with the turnover problem and College $\mathrm{A}$ is a prime example. There are several possibilities as to why the turnover problem persists at College A. This analysis will focus on the framework provided by the turnover literature presented in the previous section.

\section{Recruiting strategy}

College A does not have a known recruiting strategy in place. When a position becomes vacant at College A, the director of the particular department with the vacancy has an opportunity to "re-evaluate" the job description before posting the position. The position is then posted and human resources is flooded with resumes. One person in human resources usually arbitrarily screens the resumes, looking for "past careers that match the job description." Adequate resumes are then passed to the director of the department at which time, "each 
department has its own way of doing things." This is an important illustration to introduce the college's view of a recruitment strategy, before delving into the specifics of the OIA. Kay's and Phan's (2002) seven criteria for a successful recruiting strategy will be used to analyze the recruiting strategy in the OIA at College A.

\section{A carefully articulated and well-} understood business strategy. The history of the instabilities of College A is long and contributes to the turnover problem the OIA faces. Identity shifts of the college and the discontinuity of presidential leadership disrupted the stability of the institution and impeded the vision of the college for many years. As a result, the college fell into a grave fiscal crisis in the early 1990s. Therefore, the current president's goals have focused almost exclusively on finances. For the last ten years, the president and the vice president for Administration have worked exclusively on making the college financially solvent. In doing so, the college has decreased its debt and has acquired more assets now than ever before in its history. The president and the vice president for Administration have achieved this through sound fiscal management and without substantial assistance of outside funding sources solicited by the OIA.

Although financial solvency is crucial to the college's survival, the business strategy has been and continues to be narrow in focus. Educational, effectiveness, and human capital (people) goals are minimized and do not appear to be part of a comprehensive college plan. There has been little communication of any business strategy at the college.
Because of the senior leadership's focus, it seems as though little money has been spent on the people of the institution.

The vice president of the OIA never communicated a business strategy. The lack of direction from the vice president was problematic. There has never been a discussion about a business strategy in the OIA. On many occasions staff members had asked the vice president to set goals and establish a business plan. She ignored the requests as if they were irrelevant to the success of the operation. When the new director for annual giving was hired, he went to the vice president on two different occasions to discuss strategy. The new director was shocked that the vice president told him to come up with his own.

The lack of business strategy in the OIA is problematic because staff personnel do not have a sense of purpose in their work. The employees of the OIA often work aimlessly, not knowing what their goals are and having no vision to inspire them. The former associate director of annual giving brought in many gifts above $\$ 1,000$; however, when he approached the vice president to establish a realistic goal of just how many the OIA needed to get into this category, she dismissed his request. She said that the institution would never see more than the 200 people who gave at that level.

Without a business strategy in place it seems nearly impossible to know what kind of people the OIA needs to hire. What skills and talents are needed to support the business strategy? What types of behaviors are needed to accomplish the goals of the strategy? With no strategy in place, it is nearly impossible to conceive the other six 
elements of a successful recruiting strategy. Not only was a lack of goal or strategy de-motivating, it also begins the recruiting process aimlessly. Immediately, understanding College A's turnover problem is more lucid.

\section{Current and comprehensive turnover} data, recruitment cost data, and retention data. When asked, the director of human resources said the senior administration had been concerned about the high turnover in the OIA. The director said that there were some concerns, but there was little that they could do about it. No turnover statistics existed for the department. Without these important data, the problem's impact is not as salient in terms of its financial impact on the division and more importantly, on the College. Indeed, the problem will persist if there is no sense of urgency in the OIA and with the senior administration.

Competency models that directly support the business strategy. Neither the OIA nor the Office of Human Resources has a competency model for recruiting. Without extensive competency models, the OIA is aimlessly hiring staff members. The office does not describe formally the kinds of people it is seeking to attract. The most recent example is in the hiring of a new director of Annual Giving. There was no discussion about what kind of skills the office was looking to fill for this particular position. The associate director of Annual Giving, already overwhelmed with responsibility, was put in-charge of the recruitment process. When the associate director went to the vice president to seek guidance for what he should be searching for, her response was to use his best judgment. Not only could the employees they hire not be right for the institution, the employee is not given a fair chance to assess the qualifications for the job for which they are applying. It is no surprise that people do not stay in their positions very long.

\section{A thorough inventory of current} competency demographics (Where in the organization and with whom do necessary competencies reside? What gap does this recruit fill?). Neither the OIA nor the Office of Human

Resources has a thorough inventory of current competency demographics. The lack of competency assessment within the organization is just as detrimental as not having a competency model. Within the OIA, there could be five people with the same competencies, when the organization only needs one person with those abilities. The absence of such planning is another illustration on the impact of turnover in the OIA.

\section{Accurate and relevant position} descriptions, including a description of career/development tracks. The OIA does have a description for each of the positions in the division. Whether it is relevant or accurate is questionable. For instance, the coordinator of Annual Giving is the manager of the phone-a-thon, but in the job description it does not mention phone-a-thon anywhere. The OIA does a good updating or changing job descriptions upon vacancies, but again their accuracy is in question. Very few people who accept a position in the OIA ever see their job description. When asked, several members of the 
OIA said that they had never seen their job description. If people are asked to do different things than what they originally thought they were hired for, resentment often builds and can lead to unhappiness.

In the OIA, because of the severe turnover problem and being short staffed to begin with, members within the OIA begin taking on other people's roles. Oftentimes people are doing two to three jobs in one. There is no mention of a career or development track in any of the position descriptions. People want to know that there is growth opportunity when they accept a position.

Intimate knowledge of market/ competitor opportunities along with pay and incentive packages. Neither the OIA nor the Office of Human Resources was able to disclose intimate knowledge of the market or competitor opportunities with pay and incentive packages. Without intimate knowledge of the market rate for professionals, the OIA does not have the means by which to compete with other institutions. They often lose out on top candidates because they are offering lower salaries. For instance, the director of Annual Giving in the OIA was offered a similar position at another institution for substantially more money. Furthermore, because the OIA offers less money and they do not realize that they pay lower than their competitors, they end up hiring less committed staff members, who take the job temporarily while they look for something else.

A sound candidate evaluation process (systematic rigorous evaluation criteria vis-à-vis skills and competencies, culture, fit, background check, behavioral traits). Once the vice president of the OIA received the resumes presented by the Office of Human Resources, the evaluation process is entirely up to her. The vice president usually determines who is granted an interview and who is not. At that point the vice president meets with candidates and then determines if the candidate should meet the other members of the team with which he or she would work. The process, though systematic, is not rigorous and does not meet evaluation criteria such as competencies, culture fit, and behavioral traits. The OIA does not do background checks, but does call one to two references prior to any offer being made to a candidate. It is clear that College A's OIA has little, if any recruiting strategy in place. The process seems aimless and is unaligned with a nonexistent business strategy. It is apparent that a lot of the turnover problems begin with the process in which the OIA is hiring its staff. None of the staff members who do the hiring in the OIA have had training in recruitment.

Compensation and benefits programs Although money and fringe benefits are not always the only factor involved in terminations of employment, they constitute a serious factor in understanding the problem. Like in the presented literature review, the analysis in this area will be structured under two headings, (1) cash compensation and (2) other benefits.

Cash compensation. College A's cash compensation is known to be below market. Although the 
College's salary data could not be obtained, Guidestar is a public database that has the tax returns of nonprofit organizations. On these tax returns, the organization is responsible for listing its top cash earners. Although what organizations choose to list as their top five earners seems to vary from institution to institution (some list the president, others do not), these data provide insight into College A's compensation structure compared to competitor institutions. It was clear that the overall salary structure at College A is lower than similar-sized institutions. This overall compensation strategy affects the OIA. When a few members of the OIA at College A were asked why they left, most of them said that they could earn more money elsewhere for less stress and greater opportunity.

College A must consider what it pays its staff and how that contributes to turnover. Overall, College A seems to pay less than other institutions, possibly due to its other strategic goals. Low personnel budgets prohibit the OIA from offering marketcompetitive salaries. Top candidates usually reject low offers and the OIA is not able to negotiate outside of a narrow margin. Therefore, many times, less-experienced individuals take the low offers College A makes to gain experience and then to move on to higher paying institutions. Because of poor salaries and an unclear personnel vision, the OIA hires people who are less qualified for the job function.

At College A, whether you are a high-performer or a low-performer, everyone receives the same small raise, usually between 2 and 5\% each year. There is no system in place that rewards high-performers. For instance, the director of Major Gifts has been responsible for closing very large major gifts and had not been rewarded for it. She will receive the same small raise as other people in the organization, even those who are not performing optimally. Given such a policy, keeping a talented staff is very challenging. The director of Major Gifts could leave College A and receive a substantial raise.

\section{Other benefits}

According to the members of the OIA, the health benefits seem to be reasonable. The price that employees pay for their health care benefits appears to be competitive with other institutions. College A pays 100 percent of their employee's dental plan, a perk that several members of the OIA appreciate. The College does participate in a $403(\mathrm{~b})$ retirement savings plan. However, staff members must be at the College for two years before it will contribute to their plan. Many people within the OIA argue that two years is an excessive vesting period and said that if the College matched their contributions to their retirement plan sooner, there might be added loyalty. In terms of matching amounts, College A will match up to six percent of an employee's salary. College A offers tuition remission benefits to both employees and members of employees' families. The benefit at College A takes place immediately for employees and after one year of employment for employees' families. Several members in the OIA are currently in degree programs and state that they stay at College A to receive free tuition. Because most higher education institutions do offer 
tuition remission benefits, College $\mathrm{A}$ is not unique.

The vacation and sick time at College A is generous. It offers nearly five weeks in paid vacation time off, accrued incrementally each month of employment. In addition, both offer generous sick time programs. College A does not offer a PTO program like Kay and Phan (2002) suggest to many organizations. However, it does not seem to have much of an impact at College A. When employees in the OIA were asked if vacation and sick time were adequate, many believed that it was. It is unlikely that an employee in the OIA would leave because of the lack of vacation or sick time offered. College A appears to have an adequate benefits program. The only area that could be contributing to the turnover problem there or could possibly help turn it around would be the retirement savings plan and how it is administered. The cash compensation policy, on the other hand, seems to have an extremely negative impact on retention at College $\mathrm{A}$.

Human resources programs "[It is vital to treat] the workforce as an investment rather than a cost" (Bolman, 1997, p. 117). College A's OIA does not adopt a human resources philosophy based on investment in their people. Investing in people goes beyond salary and benefits. People need to feel valued and there are many ways in which an institution's human resource strategy can implement value-added policies and procedures. When analyzing College A's human resources programs, five key elements of a human resources program will be used.
Creation and communication of a shared vision. Not only is the vision not shared in the OIA, there is no vision. As mentioned earlier in this article, there is an understood business mission to raise money. Nonetheless, there is no vision in which all the members of the OIA have gotten together to discuss the purpose and vision of the department. Bennis and Nanus (1985) suggest that vision is a "developed mental image of a possible and desirable future state of the organization...This image....may be as vague as a dream or as precise as a goal or mission statement" (p. 89). A major problem within the OIA is that the vice president of the OIA has established neither a dream nor a vision. On many occasions staff members have asked the vice president to set goals and establish standards, or even a vision. She ignores these requests as if they were irrelevant to the success of the operation.

The lack of vision in the College and the OIA is problematic because the workforce does not have a sense of purpose in their work. Clearly, inferences can be made and people are aware of the job they are hired to perform, but there is no unifying vision that bonds a community of workers together. The result is a less productive and efficient workforce. Without vision, there are no goals and strategies to attain a desired outcome. The employees of the OIA often work aimlessly, not knowing what their goals are and no vision to inspire them.

The workforce is unmotivated and dissatisfied by the lack of vision. The nonexistent vision has frustrated many employees. There is little trust in the vice president of the OIA among the staff as a competent leader. The 
director of Major Gifts, who recently went on maternity leave, is using her time off to search for a new job. She states that she is looking to learn from a vice president who establishes a strong vision and someone who sets goals for their staff. She is looking to learn from someone who can help her grow and develop her skills. Clearly, the lack of vision in the OIA and in College $\mathrm{A}$ is hurting its retention rate.

Offer praise freely. Receiving praise in the OIA is a rare occurrence. The vice president rarely lets people know that she is happy with their performance in specific situations and on an overall basis. On the contrary, she has an abundance of negative things to say about her staff and her colleagues. Praise within the OIA usually comes from peers, though it does not happen often. Perhaps because of the culture the vice president established there, when people performed well, it is very rarely that they would hear anything about it. Everyone who performs in a job function needs feedback, both positive and negative. Receiving praise is even more important for people's job satisfaction level. In the OIA, members are disillusioned and depleted because there is little to no positive feedback there. This, clearly, contributes to low morale and the high turnover in the department.

\section{Evaluation, development and} promotion from within. The way in which employees in the OIA are evaluated is very simplistic. There is a yearly performance review, completed by the directors of each department in the OIA. The performance evaluation rates employees on a scale from 1 to
5, from least satisfactory to exemplary. Employees are rated in various different areas of their job function. The vice president of the OIA, however micro-manages the process by declaring to the directors that no employee is allowed to receive a " 5 " for anything. In addition, the vice president has to sign off on all evaluation forms before sending it to human resources. Not only are the evaluations simplistic, they are onesided due to the vice president's intervention.

There are no goals established on the evaluation and because there is no performance-based pay program, the evaluations have very little to do with how an employee is rewarded or reprimanded. Poor performers are not dealt with properly. For employees who perform well, it is frustrating that they are being given the same raise and treated in the same way as those who do not. Employees who perform poorly are not encouraged to improve and are not given the appropriate tools to do so.

Education and training is also sparse in the OIA. There is little to no budget for training and learning in the annual giving department. That money has to be divided among three people in the department. The money would not cover more than one person's expenses to attend a conference. There are similarly insignificant training budgets in the other departments within the OIA. There is no formal orientation or training program in the office. There is no mentoring program. There is no formal educational program and there is little organizational development initiative. The lack of training and education negatively 
affects the OIA. Staff members need to feel as though they are learning on the job (Argyris and Schon, 1978). With neither formal nor informal training and education programs, people within the OIA do not feel as though they are growing. Several staff members have complained of feeling stagnated and stifled, overworked, but in areas that are not helping them learn. New staff members are put into their offices and forced to figure things out on their own. Many of the resignations that occur within the OIA occur within the first several months. Without even the most simple orientation program, staff members are alienated and underdeveloped immediately. Informal learning opportunities are actually suffocated.

As long as new opportunities for learning are withheld, the OIA will continue to see staff leave. The OIA does not promote within. There have been numerous opportunities for staff to advance into other positions because of high turnover.

\section{Effective communication.}

Communication is poor in the OIA. Even though the office is relatively small, communication is lacking. Oftentimes staff members find out about events and happenings that the office is going to be a part of from other divisions with the College. The communication problem begins at the top with the vice president, but then is carried down to all of the directors of each department. Staff meetings occur one time per month and the vice president makes everyone in the office talk about what they are doing. Instead of grappling with important and imperative issues and questions, the session is merely a report for her to make sure everyone is doing his or her job. Despite the small size of the office space, e-mail is the primary mode of communication. If people have questions for others in adjacent offices, they will send e-mails rather than getting up and walking over to the person's office or picking up the telephone. With an environment such as this, the feeling can often be isolating. The communication is impersonal at best within the OIA. The lack of communication contributes to turnover because employees get frustrated when they find out important details to their job function after the fact or from people who should not be telling them the news. Being unaware of important information can also make people feel disrespected or unimportant within the organization. People seek to be in environments that are open and not impeded by layers of structures that hinder communication.

Availability and flexibility. Leaders within the OIA are generally not available. The vice president does not make time to sit down with her staff members to discuss issues, nor does she set the tone that it would be okay for her staff to come to her with any problems or issues. This issue exacerbates the turnover problem within the OIA. On many occasions staff members have wanted and needed to speak to the vice president about important personal issues, but have chosen to go to human resources to do so instead. The flexibility in the office is polarized and inconsistent. On one hand, there is a tremendous amount of flexibility in time spent on the job and how much work one puts into the position. Owing to the lack of 
evaluation and accountability, many people within the OIA know that they could not get away with a lot of what they do or do not do at other institutions. The inconsistent nature of the office's flexibility can be seen as both a turnover deterrent for some and a turnover contributor for others.

\section{Implications on a national level} It is important to think about this analysis and how it can contribute to solving the turnover problem in the advancement profession on a national level. Many of the findings in this local analysis may be exemplary of other institutions and how they manage their people-from the hiring process, to how much and in what ways they reward them, and what other human resources programs they offer their staff members. Because of the time constraints of this analysis, it was not feasible to closely analyze more than one institution's turnover problem; however, in the next section, policy recommendations will be made to College A, and in turn, for higher education administrators across the country. It should not be assumed that all higher education institutions have exactly the same policies as College A; however, the solution strategy could be worthwhile for a wide array of higher education institutions.

\section{Policy Recommendations}

\section{Solution strategy for college A}

There are three important areas that, from the analysis, appear to be contributing to the turnover problem at College A. They fall into three areas: recruiting, compensation and benefits, and other human resources programs. Conclusions drawn from the analysis suggest the following solution strategy for College A's OIA.

\section{Recruiting strategy}

It is clear that College A must come up with a recruiting strategy in order to stop the persistent turnover in the advancement operation. Kay and Phan (2002) and Davenport (1999) agree, avoiding turnover begins with hiring the right people. It is evident that College A, in general, does not have specific strategies in place to hire for specific competencies that will contribute to the overall success of the organization. Though this problem is college-wide, the OIA needs to establish its own recruiting strategy, since hiring power exists exclusively within the division. Furthermore, any college-wide recruiting strategy would have to be sanctioned by the president of the institution. It is unlikely at this point that the college's senior administration will alter its course. The vice president of the OIA could go to the President's Council meetings and suggest that a college-wide policy be resurrected, but again, the likelihood of the College spending money on such a policy inception is extremely low.

It is up to the OIA to establish its own recruiting strategy. In doing so, the OIA could adopt Kay and Phan's (2002) seven elements to a successful recruiting strategy, beginning with a business strategy, which the division lacks, a comprehensive understanding of the turnover problem, and the creation of competency models for the entire division and the positions needed to accomplish the business strategy. 
- A carefully articulated and wellunderstood business strategy

- Current and comprehensive turnover data, recruitment cost data, and retention data

- Competency models that directly support the business strategy

- A thorough inventory of current competency demographics (where in the organization and with whom do necessary competencies reside? What gap does this recruit fill?)

- Accurate and relevant position descriptions, including a description of career/development tracks

- Intimate knowledge of market/ competitor opportunities along with pay and incentive packages

- A sound candidate evaluation process (systematic rigorous evaluation criteria vis-à-vis skills and competencies, culture, fit, background check, behavioral traits).

It was apparent from the analysis that the OIA has not executed or even thought through any of these elements that make up a substantial recruiting strategy. If the OIA did put a comprehensive strategy such as this one in place, it is likely that it would see a dramatic decrease in turnover.

\section{Compensation and benefits}

Cash compensation. As pointed out from the literature review and the analysis, many experts agree that in order for institutions to keep their people satisfied and from leaving, it is important to pay your people well. At College A, it is apparent that it does not pay its people well on every level.
Because of the financial state of the college and its current administration, it is unlikely that changes will be made to the salary structure; however, it is vital for the college to perform a benchmarking study. Similar to the recruiting strategy, if the senior administration is unwilling to embark on a college-wide benchmarking study, then it is important for the OIA to do one itself. Perhaps the vice president of the OIA could use some of her budget to have a consultant conduct a smallscale benchmarking study within the OIA. With the data, that would most likely show each and every staff member in the office far below market salaries, perhaps the vice president of the OIA could get some leverage with the president and the vice president for Administration. Since these two members of the senior administration are preoccupied with keeping expenses down, perhaps a presentation of the study's findings is vital. At the same time, it would be important for the vice president of the OIA to show the two senior members of the administration a cost analysis and comparison. This report would show them the amount of money spent on turnover each year and how increasing salaries to market levels may be one way to cut costs.

Highlighted by the analysis and specific examples, one of the major contributors to the turnover problem is indeed low salaries. Staff members are leaving, simply to earn a better living. If College A's OIA has no idea where it stands in the market of higher education in its region, then it will continue to see its people leave. And in relationship to the importance of a recruiting strategy, perhaps higher salaries would attract people with 
competencies that better match the business strategy of the OIA. Paying people what they know they deserve and could earn elsewhere may have an enormous impact on the OIA's high turnover rate.

Another strategy the OIA should consider is paying employees based on performance. This strategy would involve overhauling the OIA's simplistic evaluation process. It is recommended that managers will meet with their employees three times per year. First, the two should come up with agreed upon, measurable goals and objectives for the upcoming fiscal year. About four months into the year, the two should meet again to discuss progress on those measurable goals by assessing where the employee is on each of the goals and objectives. If it looks as though the employee will not meet the goals, it should be up to the manager to either (a) re-establish more realistic goals or (b) keep the current goals and give the employee more assistance in attaining them. The third meeting should be to discuss the outcomes of the year, including whether or not the employee met the goals and objectives and discuss why or why not. Based on these three meetings, the employee's raise should be established.

Currently College A's OIA personnel all receive the same raises despite performance. If people are being paid for what they are doing and doing well, then it is more likely that they will feel appreciated and valued. With feelings of appreciation and value comes retention. On the other hand, if employees persistently perform poorly then appropriate action should also be taken.
Other benefits. Overall, College A's other benefits seem to be in line with other colleges and universities. It does not appear to be a major contributor to the turnover problem within the OIA. The only exception is the 403(b) retirement savings plan. To enhance this benefit, College A may consider reducing the vesting period before it begins to match employees' contributions. The current vesting period is two years and it is very lengthy compared to other institutions of higher education. Although the College may see the vesting period as an incentive to stay, it actually may be an incentive to leave. Other colleges and universities in the region have vesting periods of one year or less. This change in college policy would have to come from the president. The vice president of the OIA could make a recommendation to the president as a part of her benchmarking study, attempting to show the president that the vesting period is lengthy and if shortened, it could retain employees.

\section{Other human resources programs}

Communication of a shared vision. A vision must be established. A clear, coherent vision, which has solicited the ideas of the OIA employees should support and contribute to the college vision, no matter how narrow it may be. Once the vision is established, it must be communicated throughout the staff frequently. The leadership of the OIA can do that by holding regular staff meetings where the vision is reminded. The leadership can create a vision statement and post it somewhere visible in the office. The directors of the department can be charged with 
having to come up with their own vision statements stating how their team is going to help attain the vision of the OIA. Through the establishment of a vision, the OIA will feel a sense of purpose and they will feel as though they have purpose and a community of commitment to that vision. Without a vision, the members of the OIA will continue to feel as though they are working aimlessly. The analysis showed examples of staff members who left College A to pursue institutions that had established visions.

Offer praise freely. The members within the OIA should be praised when they accomplish goals and/or achieve successes. The majority of the feedback within the OIA is negative. The constant negative feedback has shown to alienate members of the OIA. Offering praise when praise is due could help the morale tremendously, which then could help the turnover problem, as well.

\section{Evaluation, development, and} promotion within. The current evaluation process is limited. As this solution strategy previously suggested, the evaluation process should be completely overhauled by the OIA. With the inception of a new, more comprehensive evaluation process, more opportunities for staff development will be more apparent. If employees are struggling to make their goals and objectives as set by their performance plans, then the managers of each department within the OIA should get their employees the proper resources, instruction, or training to perform.
Professional development is an area within the OIA that needs major improvement. The vice president of the OIA needs to ask for more training and development money from the president of the college. Her argument should be that she is looking to retain more staff.

The vice president should encourage her departmental directors to look within when positions become available and when a staff member has repeatedly performed above expectations and exceeded all goals. If this is the case, the staff member needs another challenge. If staff members are not challenged from within, more often than not in the OIA, they look somewhere else. Revising this policy on promotion from within could improve the OIA's turnover.

\section{Effective communication.}

Communication in the OIA is in serious need of improvement. There are simple solutions to the communication gap within the OIA. The vice president needs to call bimonthly staff meetings instead of monthly. At these staff meetings, instead of having employees report what they are doing, departments in the OIA could give an overall update. The vice president should seek agenda items from the staff and discuss them as a large group. Because the staff is small, this style of meeting should work and increase collaboration at the same time as communication. In addition, departments should hold their own meetings on a weekly or bimonthly basis. This will increase departmental communication and will ensure that the department is sharing its happenings with the other departments in the OIA. 
There should be a divisional policy against communication within the office by e-mail, unless it is last resort or someone is on vacation. When the office is less than 3,000 square feet, employees should be able to talk to one another by getting up and going to each other's offices. Otherwise, picking up the telephone is also a useful way to communicate. Many divisions in colleges or universities have their own intranet (internal website) where new hires, events, important dates, and other news can be posted. This can be an everyday source of news and updates within the OIA. Intranets are known for increasing morale and communication. Intranets can also be used for fun applications such as adding employee birthdates or posting holiday parties and events.

Availability and flexibility. All managers within the OIA, most importantly the vice president, should make themselves available to their staff members. This should be communicated and carried out by example. Staff members within the OIA need to feel safe and supported by the superiors. Without that basic need met, people will not trust the division and will not feel comfortable. If people cannot go to a manager to discuss a personal or professional problem, then it is likely that they will go elsewhere where they can have these needs met. The OIA should be consistent and careful in its flexibility options. There should be policies in place for receiving compensatory time if an employee works several hours of unpaid overtime. Certain people's hours should be watched closely and others' not, unless there is evidence of a person taking advantage of the OIA. An overall sense of flexibility should be in place for staff members. For instance, if a parent has to pick up a child at school at the last minute, then the OIA environment should be supportive and reasonably fair when approaching matters such as these. Little items such as these have proven to go a long way toward retaining employees.

\section{Solution strategy at the national level}

From the analysis of College A, there are several recommendations that can be made to higher education professionals regarding the turnover problem their advancement offices. Similar to the local example, the three areas that they should think about are: recruiting, compensation and benefits, and other human resources programs.

It is clear from the analysis that all college and university advancement administrators need to be thinking more about the people they hire. Vice presidents of Advancement across the nation should be made aware of the importance of establishing recruiting strategies. Although recruiting strategies should be conceptualized by the entire senior administration, if vice presidents do not receive support from their superiors, then they should take it upon themselves to create a strategy on their own, with special attention to the hiring of people who are going to show loyalty and commitment to the organization.

Kay and Phan (2002) offer excellent recommendations to organizations and how to adopt a recruiting strategy specific to the needs of that particular organization. Like the vice president at College A, other colleges and universities that are facing similarly dismal retention rates should think 
about each of the seven elements and how they can be customized to fit their organization. Finding a "right" fit is a difficult task, but implementing a strategy forces hiring managers to think about issues that otherwise go unnoticed. These issues could be the difference between an employee leaving or staying. Though a recruiting strategy is essential, and hiring a talented staff is a challenge, keeping them challenged and satisfied is an entirely different task.

It is clear that organizations must pay their people well. Benchmarking studies, much like the ones conducted by CASE should be done not only by national organizations, but also by individual institutions. Every college and university should know where they stand in terms of paying their employees versus their local and national competitors. The war for talent is intense and cash compensation can be an easy reason for people to choose to leave a post to begin anew. University and college advancement leaders need to eliminate this element from the turnover equation. It is likely that advancement leaders must convince their superiors, most likely presidents or chancellors, that paying their staff is vital for success.

Each advancement office should know how much money it is losing to turnover and how much could be gained if they paid better. Robin Netherton's (2002) paper reported that the individuals earning the lowest salaries were the quickest to quit. Perhaps some colleges and universities should consider paying the entry-level and junior-level employees better.

Paying people what they know they deserve and could earn elsewhere may have an enormous impact on the high turnover rate. If advancement offices know where they stand and then can pay their staff at market level or better, then, they can be confident that salary has little to do with their turnover problem.

Because a development officer's job is to bring in money, universities and colleges should consider paying their advancement professionals based on performance. Each employee should establish agreed upon and measurable goals and objectives. Employees should be given every opportunity to obtain their goals and objectives. If they hit their goals, then they should be awarded accordingly. If not, they should be given specific appraisal benchmarks to hit in attempt to improve. If improvement does not occur, then employees should be terminated. It is unfair to keep employees who underperform. It is unfair to the employee and to the institution. Furthermore, when people are paid for what they do well, then they will feel valued. With feelings of appreciation and value comes come retention. On the other hand, when employees see colleagues who perform with less quality than what they are and they are given the same awards and raises, dissention will infiltrate permeate the organization. Universities and college advancement offices must re-evaluate their performance standards and how people paid for their work quality.

Another recommendation would call for all advancement leaders to think about offering bonuses for stellar performances. If budgets allow, outstanding performers-which classification should be established in writing and widely communicatedshould be given bonuses to show 
appreciation. Many people are motivated by money and sometimes minimal bonuses of even $\$ 2,000$ to $\$ 3,000$ could mean the difference between loyalty and frustration. Team bonuses can also be a creative way of using bonuses. All bonus programs have ethical implications and the profession should continue to explore this topic. Commission-based compensation has been deemed unethical by many organizations. It is also important to remember, as highlighted throughout this analysis, that money is not the only motivating factor.

In general, universities and colleges are known to have excellent benefits packages. Perhaps because they are not able to offer as much cash compensation as in the private sector, other benefits are usually competitive. Similar to cash compensation, the one recommendation that can be made to advancement operations across the county is to do a benchmarking study of other institutions in terms of the other benefits they offer. Specifically, they should consider the length of time necessary to be vested in their 403(b) plans and to what degree they match their employees' contributions. Although many of these decisions are made by presidents or chancellors of institutions, vice presidents of advancement could spearhead such benchmarking projects to show their university leaders what competing institutions are offering.

All organizations must have clearly stated and established visions. These visions should be bought into and contributed to by the employees within the advancement operation. All employees should feel attached or responsible to the organization to some degree. By establishing a shared vision, there is an understanding of what is expected of employees and the goals that the organization is working towards. Without a vision, the members feel as though they are working aimlessly. If development operations do not have a vision, the leadership of that division should make it a priority to establish one, and then communicate it effectively and often.

All university and college advancement operations should selfassess on if, or how it praises its employees. Is there a culture that offers praise openly and often? Are people told that they do a good job, not just when they do a poor job? Leaders of advancement operations, especially if they do not have budgets to offer bonuses, should do whatever they can to praise their employees through verbal communication, written communication, or even small rewards such as minimal gift certificates or paid time off. Simple strategies for offering praise can make an enormous impact on employee loyalty.

Many advancement divisions within institutions of higher education have simplistic evaluation processes. These evaluations may consist of one meeting each year and are usually not based upon goals and objectives. It is recommended that university and college advancement offices around the county re-think their evaluation processes and determine whether or not it is effective. Every advancement professional deserves an honest evaluation. If someone is performing well, he or she should know about it, as, conversely, professionals who are not performing should also be made aware of their deficiencies. Stellar performers should be rewarded and 
those performing at less than optimal levels should be given the tools to improve.

Professional development also appears to be an important area about which advancement leaders should be aware. Aside from cash compensation and good benefits, one of the most stated reasons for leaving was lack of professional development (Netherton, 2002). University and college advancement operations must look at its staff development programs and make them a priority. Training and education programs should be established and should be a major budgetary consideration. These opportunities should exist both externally and internally.

Having opportunities for growth within a division is also crucial to stopping the reducing turnover dilemma. Vice presidents should be aware of talented staff members and should think ahead to opportunities for them to advance, not only in terms of salary, but also in terms of responsibility. If college and university advancement leaders made this a priority, perhaps the amount of turnover these offices face would be reduced.

Good communication is essential. Everyone wants to make sure that they are in the loop. Lack of communication can damage morale. Advancement leaders should call regular meetings to inform employees of essential policy shifts and coming events. Because the advancement operation is such an integral part of a university or college, the vice presidents of these divisions must make it a priority to communicate changes, new programs, awards, or accolades the institution receives.
As a sales force, in essence, advancement officers need to be well-informed not only of divisional happenings, but also of university or college news and events. As stated in the recommendations to College A, a great way to communicate internally is by establishing an intranet. Especially for large advancement operations where staffs can be as large as 300 members, an intranet is a great way to keep people up to date. Information on new hires, events, important dates, and other news can be posted. This can be an everyday source of news and updates within advancement operations across the county.

It is recommended that development leaders should assess their availability and flexibility. Are they therefore available to their staff members when they are in professional or personal need? Is the organization flexible for employees with children? These are questions that leaders must ask themselves and then figure out how these policies contribute to individuals leaving the division. And if policies can be shifted, it is also important for leaders to assess whether or not changes in policy make a major difference in turnover rates. Little things such as flexibility and openness can have a huge impact on employee satisfaction and loyalty. College and university advancement leaders must be aware of these conscious or even unconscious policies how various policies affect turnover, in both intended and unintended ways.

\section{Conclusion}

The recommendations made in this article could greatly improve the 
turnover rates around the country, if only the leaders of advancement divisions thought more about their staff members as they would want to be thought of by their managers. It is critical that more research be completed in this area to help advancement and higher education leaders better understand the policies they need to put in place to combat this very serious issue.

\section{References}

Argyris, C. and Schon, D. (1978), Organizational Learning: A Theory of Action Perspective, Addison Wesley, Reading, MA.

American Management Association (2002), “How to cut costs and improve retention," HR Focus, 79,5 , pp. 3-5.

Bennis, W. and Nanus, B. (1985), Leaders: The Strategies for Taking Charge, Harper \& Row, New York, NY.

Bolman, L.G. (1997), Reframing Organizations: Artistry, Choice, and Leadership, Jossey-Bass Publishers, San Francisco, CA.

Davenport, T.O. (1999), Human Capital, Josey-Bass Publishers, San Francisco, CA.

Duronio, M.A. (1996), "In defense of development," Currents, November/December, pp. 64-65.

Flannery, T. and Sanes, R. (2003), "People programs pay off," Financial Executive, 19, 5, pp. 56-58.

Gaynor, A.K. (1998), Analyzing Problems in Schools and School Systems: A Theoretical Approach, Lawrence Erlbaum Associates, Mahwah, NJ.
Gering, J. and Conner, J. (2002), “A strategic approach to employee retention,"

Healthcare Financial Management, 56, 11, pp. 40-44.

Gish, J. (2003), "Managing a professional workforce," Supervision, 64, 7, pp. 8-10.

Gwynne, P. (2002), "Keeping the right people," MIT Sloan Management Review, 43, 2, p. 19.

Hacker, C. (2003), "Turnover: a silent profit killer," Information Systems Management, 20, 2, pp. 14-18.

Helm, P.R. (1993), "A farewell to prospects," Currents, March, pp. 11-14.

Kay, I. and Phan, B. (2002), The Human Capital Edge: 21 People Management Practices Your Company Must Implement (Or Avoid) To Maximize Shareholder Value, McGraw-Hill, New York, NY.

Michaud, L. (2002), "Five keys to maximize employee retention," National Public Accountant, March, pp. 36-37.

Miskel, C. and Ogawa, R. (1988), "Work motivation, job satisfaction, and climate," in N.J. Boyan (Ed.), Handbook of Research on Educational Administration, Longman, New York/London, pp. 279-304.

Netherton, R. (2002), "Advancement's paycheck," Currents, July/August, pp. 1-7.

Satava, D. (2003), “The A to Z of keeping staff," Journal of Accountancy, 195, 4, pp. 67-70.

Shoemaker, D. (1995), “Exit, stage left,” Currents, November/December, pp. 19-24.

Thomas, E.G. (1996), “Turnover trends,” Currents, September, pp. 28-34.

Watson Wyatt Worldwide (2000), The Human Capital Index: Linking Human Capital and Shareholder Value. [brochure].

Worder, V.L. (2002), “Tips for keeping top performers," Association Management, 54, 13, pp. 71. 